\title{
A method of producing car mufflers by wrapping sheet metal
}

\author{
Metoda wytwarzania tłumików samochodowych poprzez zawijanie blachy
}

\author{
PAWEt BAtON \\ JACEK CIEŚLIK \\ ŁUKASZ HALAMA \\ BARTŁOMIEJ KIEŁBASA
}

\author{
TOMASZ LACH \\ MARCIN LESIŃSKI \\ DOMINIK ŁAJCZAK \\ EDWARD REJMAN*
}

DOI: https://doi.org/10.17814/mechanik.2020.5-6.11

The cold pressing of deep-drawing steel parts of a car muffler encounters blank quality problems, i.e. springback. For this reason, the stamping tool requires compensation of the springback effect by using additional operations, e.g. by calibration. The paper focuses on testing the method of forming processes by wrapping sheet metal on a special tool using servo drives, gears and crankshaft to exert pressure.

KEYWORDS: muffler, tailpipe, plastic forming, stamping, forming, deep drawing steel, automotive

Tłoczenie na zimno głęboko tłocznych stali, które stosuje się na części tłumików samochodowych, napotyka problemy związane z jakością wytłoczki, tj. ze sprężynowaniem. $Z$ tego względu narzędzie tłoczące wymaga kompensacji efektu sprężynowania poprzez wykonanie dodatkowych operacji, np. kalibracji. W pracy badano metodę formowania, polegającą na obróbce bezubytkowej przez zawijanie blachy na specjalnym przyrządzie oraz urządzeniu wykorzystującym serwonapędy, przekładnię i wał korbowy do wywierania nacisku.

SŁOWA KLUCZOWE: tłumik, rura wydechowa, obróbka plastyczna, tłoczenie, formowanie, stal głęboko tłoczna, motoryzacja

\section{Wprowadzenie: technologia wytwarzania elementów samochodowych formowanych metodą obróbki plastycznej}

Mimo licznych doniesień nt. opracowywania i wdrażania do produkcji samochodów ze stopów aluminium, stopów magnezu, kompozytów i tworzyw sztucznych dominującym materiałem w przemyśle motoryzacyjnym nadal są stale (rys. 1) - nie tylko ze względów ekonomicznych, lecz także z uwagi na konkurencyjne właściwości (takie jak prosta zmiana sztywności konstrukcji) i możliwości recyklingu. Dzięki kilku międzynarodowym programom, zrealizowanym w ostatnich 15 latach w Europie, Japonii i USA, odkryto nowe atrakcyjne rozwią- zania bazujące na używanych dotychczas materiałach. Spełniają one wymagania dotyczące redukcji masy, co ma wpływ na zmniejszenie zużycia paliwa, a także zapewniają większe bezpieczeństwo bierne pasażerów. Obecnie elementy konstrukcyjne wykonuje się z cienkich blach ze stali głęboko tłocznych o małych przekrojach, umożliwiających uzyskanie bardzo złożonych kształtów. Do takich materiałów należą stale typu DC (głęboko tłoczne) o wysokich parametrach plastycznych, nawet do ok. $A_{80}=40 \div 60 \%$ [1-3].

Oczekiwania nabywców samochodów co do ich jakości dotyczą głównie: wyglądu zewnętrznego, bezpieczeństwa, komfortu, wysokiej wydajności silnika i niskiego zużycia paliwa. Wyższe standardy komfortu i bezpieczeństwa spowodowały wzrost średniej masy pojazdu ze względu na dużą ilość przewodów i układów scalonych. Dlatego wciąż poszukuje się nowych rozwiązań w celu zapewnienia optymalnej struktury nośnej i masy oraz pozytywnych wyników testów wytrzymałościowych. To zadanie jest ułatwione dzięki zastosowaniu metod CAE, zwłaszcza w odniesieniu do metod formowania materiału.

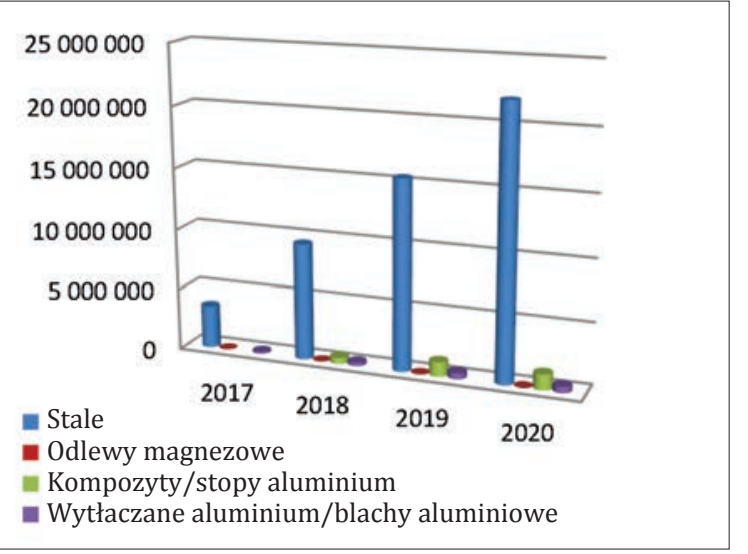

Fig. 1. Various types of materials used for plastic forming in the automotive industry

Rys. 1. Różnego typu materiały wykorzystywane do obróbki plastycznej w przemyśle motoryzacyjnym

\footnotetext{
* Dr inż. Paweł Bałon, balonpawel@gmail.com, https://orcid.org/0000-0003-3136-7908 - Akademia Górniczo-Hutnicza, Kraków, Polska

Dr hab. inż. prof. nadzw. Jacek Cieślik, cieslik@agh.edu.pl, https://orcid.org/0000-0002-0203-5149 - Akademia Górniczo-Hutnicza, Kraków, Polska

Mgr Łukasz Halama, lhalama@ulter.com.pl - Ulter-Sport Sp. z o.o., Węgierska Górka, Polska

Mgr inż. Bartłomiej Kiełbasa, bartek.kielbasa@gmail.com, https://orcid.org/0000-0002-3116-2251 - Akademia Górniczo-Hutnicza, Kraków, Polska

Mgr inż. Tomasz Lach, tlach@ulter.com.pl - Ulter-Sport Sp. z o.o., Węgierska Górka, Polska

Mgr inż. Marcin Lesiński, mlesinski@ulter.com.pl - Ulter-Sport Sp. z o.o., Węgierska Górka, Polska

Inż. Dominik Łajczak, dlajczak@ulter.com.pl - Ulter-Sport Sp. z o.o., Węgierska Górka, Polska

Dr inż. Edward Rejman, erejman@prz.edu.pl, https://orcid.org/0000-0003-4716-7613 - Politechnika Rzeszowska im. Ignacego Łukasiewicza, Rzeszów, Polska
} 
Formowalność jest definiowana jako zdolność do formowania półfabrykatu dla zaprojektowanej geometrii kształtu, bez żadnych błędów, w określonych warunkach procesu. Proces formowania można podzielić na następujące etapy:

- opracowanie projektu produktu (zdefiniowanie kształtu części i jej przeznaczenia),

- określenie właściwości materiału,

- sformułowanie warunków brzegowych,

- rozwój procesów formowania,

- rozwój projektu (wersje rozwojowe).

Według badań nowe wymagania stawiane w ostatnich latach częściom samochodowym koncentrują się na determinowaniu jakości procesu formowania dzięki pozyskiwaniu takich informacji, jak: jakość części, odkształcenia sprężyste, tolerancja wymiarów, efektywność produkcji i montażu, zmęczenie i odporność na zderzenia. Spełnienie tych wymagań stało się łatwiejsze dzięki wykorzystaniu odpowiednich materiałów: stopów aluminium (70XX), stali o ultrawysokiej wytrzymałości (AHSS) lub stali głęboko tłocznych (DC), umożliwiających uzyskanie bardzo złożonych kształtów. W przypadku bieżącego dostępu do analiz tłoczenia, które są wspierane przez testy odkształcalności, produkcja części charakteryzuje się mniejszą ilością braków i dużą wydajnością. Oprogramowanie nowej generacji jest więc niezbędnym narzędziem do użytku przemysłowego.

Obecnie w motoryzacji stosuje się głównie konwencjonalne stale niskoemisyjne, walcowane na gorąco i na zimno. Stale nowej generacji wymagają specjalnego przetwarzania, co prowadzi do powstania bardziej złożonych struktur. Dominującą metodą montażu zespołów samochodowych pozostaje oporowe zgrzewanie punktowe, mimo że następuje rozwój spawania, lutowania laserowego, klejenia, nitowania i zaciskania [4-7], a to wymusza dobór odpowiednich materiałów i warunków przeprowadzenia procesu.

\section{Proces technologiczny obróbki plastycznej elementów tłumika}

W ramach procesu technologicznego kształtowania elementów tłumików samochodowych wykonuje się przede wszystkim operacje gięcia, walcowania i tłoczenia. Zasadniczo te operacje powtarzają się w przypadku wszystkich części występujących w tłumiku.

Kształtowanie elementów polega na obróbce plastycznej na zimno materiału w postaci blach zimnowalcowanych, głęboko tłocznych. Proces obejmuje następujące operacje:

- cięcie wsadów z taśm blachy za pomocą gilotyn do cięcia blach,

- wytłaczanie znaku firmowego za pomocą pras mimośrodowych,

- gięcie blachy, wykrawanie i przetłaczanie otworów za pomocą pras hydraulicznych,

- kształtowanie płaszczy z wykorzystaniem specjalnej zwijarki ręcznej,

- spawanie wzdłużnego szwu płaszcza z wykorzystaniem robota spawalniczego wyposażonego w źródło (spawarkę do spawania metodą TIG w osłonie gazu obojętnego).

Zastosowanie wielu operacji związanych z przeróbką plastyczną wynika ze skomplikowanej geometrii części oraz oczekiwań klientów co do jej estetyki. Dodatkową trudnością jest duża liczba wariantów zdefiniowanych kształtów geometrycznych tłumików w zależności od konkretnych wymagań oraz danego modelu (rys. 2). To wszystko komplikuje produkcję, zwłaszcza jednostkową, ze względu na konieczność wytworzenia niejednokrotnie skomplikowanego i drogiego oprzyrządowania w postaci tłoczników lub wykorzystania specjalnego układu pras do formowania poprzez hydroforming, które muszą zachować szczelność medium formującego - ośrodka ciekłego, np. wody pod wysokim ciśnieniem $[8,9]$.

\begin{tabular}{|c|c|c|}
\hline $\begin{array}{c}\text { Grupa asortymentowa } \\
\text { (symbol cyfrowy płaszcza) }\end{array}$ & $\begin{array}{c}\text { Nazwa } \\
\text { zwyczajowa }\end{array}$ & $\begin{array}{c}\text { Wygląd } \\
\text { docisku }\end{array}$ \\
\hline 200 & mały owal \\
\hline 201 & duży owal \\
\hline 202 & trapez \\
\hline 203 & trójkąt \\
\hline 204 & prostokąt \\
\hline
\end{tabular}

Fig. 2. Types and geometries of possible clamps used for machining car muffler shapes

Rys. 2. Typy i geometrie możliwych docisków stosowanych do obróbki kształtów tłumików samochodowych

\section{Proces kształtowania płaszcza}

Jednym z newralgicznych elementów tłumika jest płaszcz. Decyduje on o funkcjonalności, możliwości zabudowy w pojeździe oraz trwałości tłumika. Kształtowanie płaszcza przysparza producentom najwięcej trudności. W związku z tym opracowano własną nowatorską technologię wykonania tego elementu. Jest ona następująca:

1. Cięcie pasów. Arkusz blachy jest cięty na pasy o zadanych wymiarach, które zależą od rodzaju płaszcza i jego długości oraz od wymiarów arkusza blachy.

2. Cięcie wsadów do formowania. Pasy wycięte $\mathrm{w}$ poprzedniej operacji należy pociąć na formatki o wymiarach podanych w karcie technologicznej. Są to wymiary rozwinięcia danego płaszcza, zależne od kształtu oraz zastosowanego materiału.

3. Wybijanie (wycinanie) otworu w odpowiednim miejscu za pomocą wykrojnika o wymaganej średnicy.

4. Kształtowanie powierzchni płaszcza (zwijanie blachy) do odpowiedniego kształtu na zwijarce.

5. Zaginanie usztywnień szwu na prasie uzbrojonej w dogniatak oraz pryzmę. Zaginanie następuje z obu stron.

6. Jednostronne zaginanie brzegu blachy na prasie uzbrojonej w dogniatak. 


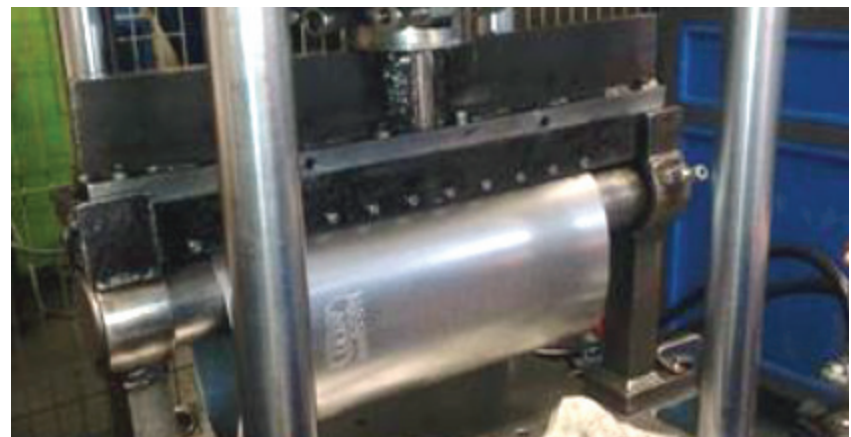

Fig. 3. Calibration operation to eliminate springback

Rys. 3. Operacja kalibracji mająca na celu wyeliminowanie sprężynowania

7. Gięcie wstępne. Na ręcznej zwijarce możliwe jest zwinięcie tylko płaszczy walcowych. Pozostałe kształty walcuje się wstępnie do uzyskania kształtu połowy elipsy.

8. Gięcie końcowe. Gięcie nadające pożądany kształt wykonuje się na prasie hydraulicznej. Proces polega na ułożeniu blachy na specjalnych, dopasowanych do rodzaju płaszcza matrycach. Stempel dociskający jest ułożony wzdłuż linii gięcia. W zależności od rodzaju płaszcza wykonuje się od jednego do czterech gięć.

9. Dotłaczanie blachy, polegające na złożeniu wcześniej zagiętych krawędzi, a następnie na zagniataniu tych krawędzi dogniatakiem na pryzmie, na prasie hydraulicznej.

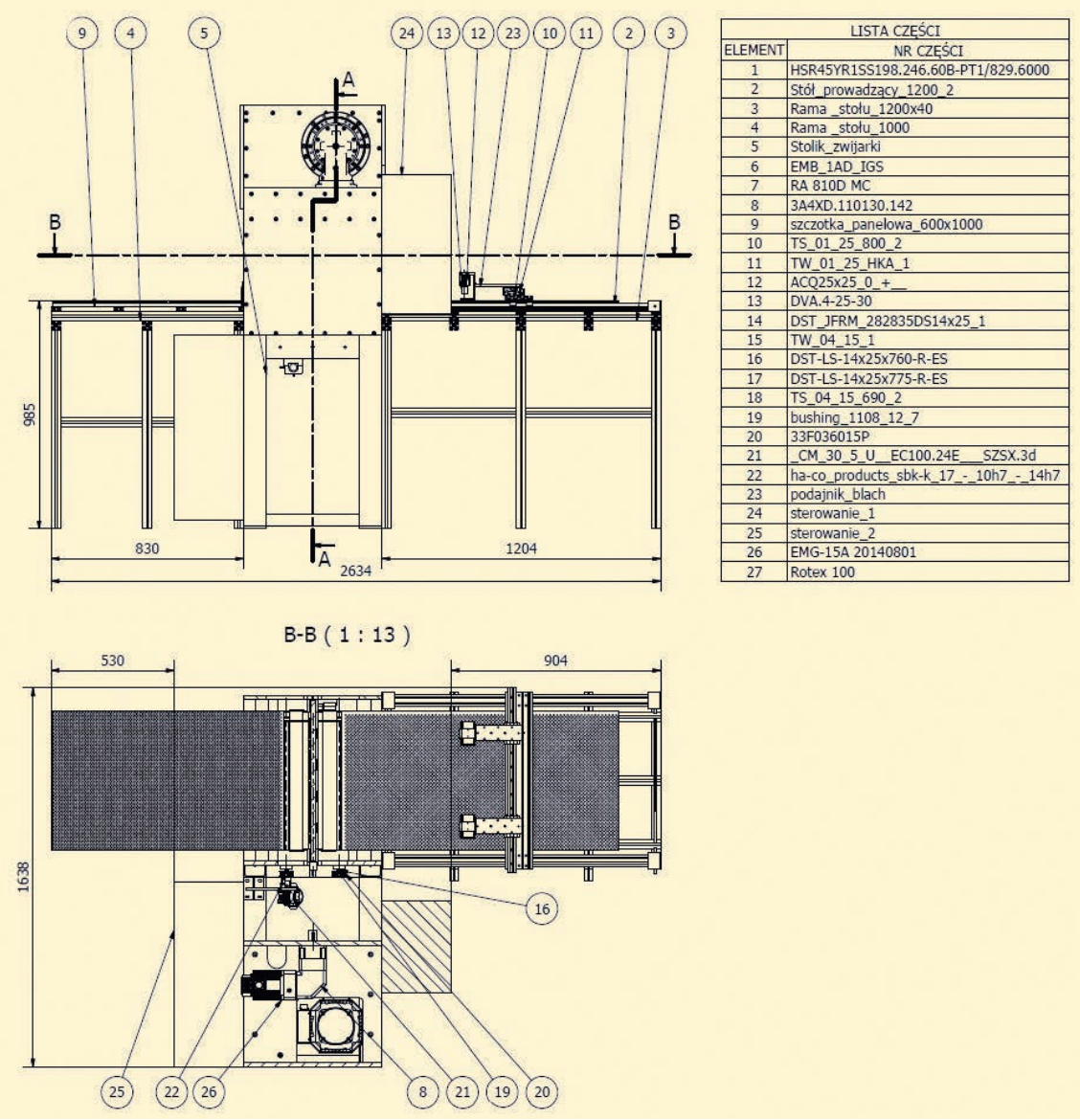

Fig. 4. An innovative device for forming steel sheets, using servo drives and enabling the production of elements with different geometries

Rys. 4. Nowatorskie urządzenie do formowania blach stalowych, wykorzystujące serwonapędy i umożliwiające wykonywanie elementów o różnej geometrii
10. Zaginanie rolką. Jest to operacja polegająca na walcowaniu wcześniej zagniecionych krawędzi blachy, co powoduje, że powierzchnia uzyskuje karby, dzięki czemu połączenie ma większą wytrzymałość i szczelność.

11. Kalibracja. Jest to ostatnia operacja formowania płaszcza. Polega na wtłoczeniu w złożony płaszcz odpowiedniej matrycy, aby nadać mu pożądane wymiary i kształt. Tę operację wykonuje się na prasie hydraulicznej (rys. 3).

\section{Opis nowatorskiego urządzenia do formowania blach stalowych, wykorzystującego serwonapędy i umożliwiającego wykonywanie elementów o dowolnej geometrii}

Opracowana w ramach badań własnych maszyna ZBTL-2017 służy do kształtowania i formowania blach stalowych o grubości do $2 \mathrm{~mm}$. Blachy są kształtowane za pomocą przemieszczającego się pionowo wałka, na który wywierana jest siła nacisku - przez dwa wałki, które powodują ruch blachy w kierunku poprzecznym do pionowego wałka i formują ją do odpowiedniego kształtu. Napęd urządzenia jest realizowany przez silnik elektryczny o mocy $11 \mathrm{~kW}$ oraz przekładnię redukującą. Maszyna (rys. 4) składa się z: komory, w której umieszcza się poddawane obróbce plastycznej blachy stalowe; serwomotorów; przekładni i wału korbowego do wywierania nacisku na obrabiane części; konstrukcji nośnej; instalacji pneumatycznej; podajnika blach z układem docisku obrabianego detalu; instalacji elektrycznej; układu sterowania i wyrzutnika zwiniętych detali. Zasada działania jest następująca: pomiędzy trzy wałki (dwa dolne i jeden górny) wprowadza się arkusz blachy, który ma być poddany kształtowemu zwijaniu. Przesuw arkusza odbywa się za pomocą jednego wałka napędowego górnego, który jest jednocześnie dociskany do pozostałych dwóch, przez co wywołuje w blasze odpowiednie naprężenia i formuje tym sposobem zwijany arkusz blachy [10].

\section{Wnioski}

Przeróbka plastyczna na zimno jest najbardziej odpowiednią i wydajną metodą wytwarzania elementów tłumików samochodowych, które muszą być wykonane ze stali plastycznej, głęboko tłocznej, odpornej na wysoką temperaturę pracy. Dodatkowo, ze względu na charakter i środowisko pracy, taka stal powinna mieć odpowiednie zabezpieczenie antykorozyjne. Technologicznie musi być spawalna - jest to warunek obligatoryjny. 
Jak wykazały eksperymentalne prace badawcze prowadzone przez zespół naukowy, stosowane dotychczas technologie produkcji z wykorzystaniem szeregu narzędzi do formowania (tłoczników) w zależności od kształtu wyrobu wymagały wytworzenia kosztownego oprzyrządowania. To oprzyrządowanie wielokrotnie optymalizowano, aby wyeliminować błędy wytłoczek (takie jak fałdowanie, nadmierne pocienienie czy sprężynowanie), a to dodatkowo podnosiło koszty produkcji. Jeszcze bardziej kosztowną i mniej uniwersalną metodą było zastosowanie technologii hydroformingu.

Zastosowanie uniwersalnej maszyny do kształtowania i formowania blach stalowych o grubości do $2 \mathrm{~mm}$, zapewniającej kształtowanie blach za pomocą poruszającego się pionowo wałka, na który wywierana jest zewnętrzna siła nacisku, pozwoliło na wprowadzenie uniwersalnej metody dla tej klasy produktów. Ta technologia pozwoliła na znaczne ograniczenie liczby oprzyrządowania i błędów wytłoczek oraz zapewniła elastyczność produkcji.

Artykuł powstał na podstawie prowadzonego projektu nr POIR 01.02.00-00-0290/16 pn. „Opracowanie nowych rozwiązań technologicznych dla zastosowania w produkcji nowoczesnych tłumików i końcówek sportowych", współfinansowanego przez Narodowe Centrum Badań i Rozwoju:

- wartość projektu: 6019 079,46 zł,

- wartość dofinansowania: 3009 539,77 zł. Celem projektu jest opracowanie i wdrożenie nowych technologii do produkcji tłumików i ich komponentów.

\section{LITERATURA}

[1] Choi J.C., Kim C., Choi Y., Kim J.H., Park J.H. "An Integrated Design and CAPP System for Deep Drawing or Blanking Products". The International Journal of Advanced Manufacturing Technology. 16 (2000): 803-813.

[2] Chuko W.L., Gould J.E. "Development of Appropriate Resistance Spot Welding Practice for Transformation-Hardened Steels". Welding Journal. 81 (2002).

[3] Danzberg J., Schmaalze S. "Parametrization of the tool geometry as prerequesite for the shape optimization of tool surface". Zurich, Switzerland, 2004, 157.

[4] Atzema E.H., Duwel A., Elliott L., Neve P.F., Vegter H. "Appreciation of the determination of the Forming Limit $\mathrm{Cu}$ rve". Proceedings of the Numisheet 2002 Conference. Jeju Island, Korea.

[5] Bałon P., Świątoniowski A. "Springback compensation in cold forming process for high strength steel"; Archives of Metallurgy and Materials. 60, 4 (2015): 2471-2478.

[6] Bałon P. "An analysis of springback phenomenon in forming process". Monography. Rzeszów: Oficyna Wydawnicza Politechniki Rzeszowskiej, 2017.

[7] Bałon P., Rejman E., Kiełbasa B., Smusz R., Szostak J., Cieślik J. "Comparison of springback value of the selected structure element for cold forming and hot forming methods". AIP Conference Proceedings. 2113 (2019): 100005.

[8] Bałon P., Rejman E., Kiełbasa B., Smusz R., Szostak J., Cieślik J. "A process of forming austenitic steel using a rubber membrane and oil". AIP Conference Proceedings. 2113 (2019): 100006.

[9] Bałon P., Świątoniowski A., Szostak J., Kiełbasa B. "Springback compensation for a vehicle's steel body panel". AIP Conference Proceedings. 1896 (2017): 080001.

[10] Bałon P., Świątoniowski A., Szostak J. "Improved method of springback compensation in metal forming analysis". Strength of Materials. 48, 4 (2016): 540-550. 